\title{
White Heterosexual Men, Athletic Bodies, and the Pleasure of Unruly Racialization
}

\author{
Stefan Lawrence, Newman University
}

\begin{abstract}
In recent times, the semi-naked male athletic body has become central to the cultural imagination of late modern societies, in turn, inviting comment from social scientists of different shades on the changing gazes of heterosexual men. Interestingly, and despite frequently appearing in sport and leisure media, the racialized aspects of this change are yet to be explored fully. This article, therefore, considers how white heterosexual men (de)construct and (re)attach gendered and sexualized meanings to those male athletic bodies they struggle to define "racially." Borrowing Gilroy's use of the term "unruly," which he employs to capture those moments of multiculture that are hard to "home" culturally or geographically, I refer to this struggle as a process of unruly racialization. After analyzing interviews with twentytwo self-identifying white, British, heterosexual men, this article argues that male bodies racialized as unruly are marked with varying degrees of intrigue, jealously, admiration, and fear. I conclude by reflecting on the extent to which this cultural shift can be read as a move toward a future beyond "race."
\end{abstract}

Keywords masculinity, whiteness, sociology of the body, athletic culture, pleasure, homoeroticism, unruly racialization

\section{Introduction}

In recent times, the semi-naked male athletic body-an object that thirty years or so ago would have been confined to (what would now be considered) LGBT magazines, and/ or to hypermasculine subcultures, such as bodybuilding-has shifted from the peripheries of popular culture to the very center of the late modern cultural imagination (Shilling 2007). Today, the demand for and supply of male flesh and muscularity is unashamedly apparent and nowhere is 
This is the author's version of a journal article published in Men and Masculinities in 2019

this more obvious than in sport and leisure cultures and media. From traditional forms of sport to emergent lifestyle sports and fitness subcultures, male bodies have not only taken on new meanings and increased significance in body-obsessed societies (Howe 2011; Markula and Pringle 2006), they have become central to explorations of contemporary discourses of masculinities. This popular fascination with male athletic bodies, especially among groups of heterosexual men, has evoked much discussion among social and cultural theorists about the changing nature of contemporary masculinities and the heteromasculine gaze. Few, however, have considered the racialized aspects of this shift and thus the broader implications for both the gazers and the gazed (Robinson 2013)

This article's primary aim then is to explore how white heterosexual men (de)construct and (re)attach racialized, gendered, and sexualized meanings to male athletic bodies and the consequences of this vis-a -vis racialization. To do this, I have chosen to focus on white heterosexual men, for two main reasons. First, the literature focusing on whiteness and white people has proliferated in recent times and so too have political movements aiming to make white supremacy "more visible" (Garner 2017). The prominence of social media campaigns such as \#RhodesMustFall and \#WhyIsMyCurriculumWhite, concurrent to the growing interest in whiteness studies more broadly across the social sciences, has, in turn, prompted eminent scholars in the field to reflect on some of the divergent philosophical and political problems such expansions necessitate (see Twine and Gallagher 2008; Garner 2017). A primary concern for scholars working in this field is to avoid an unwitting "construction of monolithic and often stereotyped portrayals of [White culture and White racism]" (Carrington 2008, 428), which fails to distinguish between whitenesses of differing shades (Long and Hylton 2002). Focusing on the experiences of men who are racialized as white and who identify as heterosexual, and thus working intersectionally, allows this article to explore how power coalesces around certain social identities and how they work in conjunction with and against one another. To this end, we are better placed empirically and conceptually to avoid reproducing "a world that is orientated around whiteness" (Ahmed 2006, 138).

Second, not only do I contend that intersections matter, how it is those men who are racialized as white and who identify as heterosexual undertake, what Brah $(1996,15)$ calls, "differential racialization" is also important when attempting to understand relationships of power. By using 
This is the author's version of a journal article published in Men and Masculinities in 2019

this term, she is referring to "how different racialized groups are positioned differently vis-a " -vis one another" and to the ways in which processes and outcomes of racialization change depending on cultural context and/or an individual's social positionality. This conceptualization points to the fluid and often disjointed ways in which racialization operates, or, as Ahmed (2000) would have it, why some bodies appear strange or out of line in certain circumstances.

To extend this work, this article considers how participants racialize certain male athletic bodies as "unruly" in the context of athletic culture. By using the term unruly, I am borrowing from Gilroy (2005), who uses it to describe those moments in (British) multicultural societies when everyday events, performances of self, and/or bodies distort dominant, reified, racialized lines, and discourses (Gilroy 2017). This term, in the context of this article then, is used to reflect on those moments that operate with a "radical openness that brings conviviality alive [and that] makes a nonsense of closed, fixed and reified identity, and turns attention toward the always unpredictable mechanisms of identification" (Gilroy 2005, xv). To be clear, using such a term in such a way is not to suggest some racialized identities are "fixed" and others are not; nor is it suggest that anticategorical modes of identity formation are common. Rather, it is an attempt to reflect on what happens at those moments when dominant racialized epistemologies struggle to locate bodies neatly within preconceived (but illusory) racialized modalities and, indeed, to consider the desirability or not of encouraging such "unruliness." Critically appraising this, to this end, serves a salient political, theoretical, and epistemological purpose insofar as it is a move to confront and distort regressive Western representations of nonwhiteness (Meer and Nayak 2013; Garner 2006, 2007; Hooks 1992; Hall [1990] 1998) and, in turn, dominant (hetero)masculinities.

\section{The Research}

This research emerges from a larger study exploring the racialized aspects of mediated, male athletic bodies (Lawrence 2013). During this study, long and detailed semistructured interviews were conducted with twenty-two selfidentifying white, heterosexual, nondisabled, British men. Each interview was enriched further by the presence of a set of twelve images (including images of men who the researcher read as 'white', 'black', and 'mixed heritage'), which elicited discussion relating to the aims of the broader study. Using printed images thus aided 
This is the author's version of a journal article published in Men and Masculinities in 2019

participants to articulate their views and opinions, on certain (sensitive and difficult) matters more easily than had they not been there (Radley and Taylor 2003; Kvale 1996). Moreover, following Blaisdell (2006), I used a "race" conscious dialectic approach during interviews in order to facilitate an inclusive and participative approach which, for Hylton (2012), allows for an exploration of the importance or otherwise of the racialized aspects of the imagery. This is an especially relevant approach for any research wishing to understand better phenomena that are more commonly discussed in private but less commonly in public (Hylton and Lawrence 2016; Hughey and Matthew 2011a).

The images used were purposively selected after a thorough analysis of a year's worth of three separate men's magazines (Men's Health, Jump, and Sport). Each magazine was purposively selected for different reasons: Men's Health and Sport offered access to mainstream media imagery, given they cater to normative sporting ideals of gender and race; Jump, on the other hand, an example of niche media, was a parkour magazine which provided alternative and subversive imagery of athletic bodies (Ryu 2005; Thorpe 2008). More specifically, during this article, I focus on participants' interpretations of and discussions relating to two images from the original set of images: Karim Aun (found in Men's Health magazine; Figure 1) and Juan Manuel Vargas Risco (an advertisement which featured in Sport magazine; Figure 2). These images, as well as participants' responses to them, for reasons I will outline below, afforded insight into the productive relationships between white heterosexual men and the bodies of others.

The participants of this study were recruited from athletic environments I observed. Following others who have demonstrated consistently that sporting cultures are valuable arenas wherein sociologies of race are enriched further (Hylton 2009; Carrington 2010; Burdsey 2004, 2006), I too utilize similar environments for empirical investigation. Gyms and parkour/free-running training sessions were selected intentionally as sites for participation and observation, namely because they offered access to groups of white heterosexual men with different and often competing philosophies of the athletic body. Not only did I observe these environments, I also participated in them and kept a research diary, in which I documented my thoughts and feelings, as well as occurrences with racialized, gendered, and sexualized significance (see Conquergood 1991). I therefore entered into the research environments as a participant-as- 
observer (Gold 1958; Burgess 1991; Long 2007). Hence, not only did this method allow me to become more familiar with the study's context, it allowed me to build rapport and trust with potential interviewees as well as generate additional data.

Of those who agreed to be interviewed, all identified as white, male, heterosexual, physically active and between the ages of eighteen and forty-five. Following Frankenburg (1993), who provides a seminal text on the study of white people, this study recruited a range of selfidentifying white men to take part, all of whom were of differing political leanings, class strata, education, region of origin, age, economic background, and marital status. The participants whose testimonies are cited in this article (Scott, Sam, Sebastian, Cris, Carl, James, Bradley, Jason, Paul, Neil, Terry, David, and Dan) have all been given pseudonyms. Here, I wish to make clear the following discussion must not be read as an attempt to collapse whiteness as racialized discourse into the social category "white people" (Nayak 2007). That is because it is presented as an account of how it is those who claim ownership of powerful racialized, gendered, and sexualized identities contribute to discourses of whiteness, masculinity, and heterosexuality through their lived experience and performance of them. This is not to say they are any more authentic doers of these identities or discourses than those who do not claim them nor that others cannot also (re)affirm or contest dominant discourses. Simply put, it is not the intention of this article to explore how those who do not claim to be or identify as a white heterosexual man are implicated in such a task.

It is my intention during the following section therefore to focus closely on (1) how and why the white heterosexual men who agreed to participate in this study received, interpreted, and made sense of purposively selected media imagery and (2) how and why they use media as a way to read their own bodies as well as the bodies of other men. This methodology is designed, in part, to address media scholars' relative lack of engagement with audience interpretations of media imagery, particularly their reluctance to mark the racialized aspects of ideal male bodies (Azzarito 2009, 21). To interpret responses and interpretations, a blended "interpretive" and "reflexive" approach to interview analysis was used.

\section{The Unruly Racialization of Athletic Bodies}


This is the author's version of a journal article published in Men and Masculinities in 2019

The first image features a shirtless Karim Aun, 1 a man whose muscular physique is presented to readers of Men's Health magazine immersed by a black and white hue, smiling, showing off tattoos on his right shoulder. Aun's head is shaven and his torso is toned, smooth, and hairless. The magazine informs its readers that Aun is "South American born [in Brazil]" but his “[c]urrent home [is] Sydney, Australia." Neither Aun's first name nor surname is associated traditionally with either of his two countries of origin, meaning without further detail this brief biography offers few clues to those seeking to locate his familial ancestry and/or heritage. The body, as is often the case, is thus integral to such an endeavor. In this case, however, the color has been drained from the image, meaning a commonly used (but of course problematic) somatic marker of ethnicity is missing-expanding the perceptual space for confusion and ambiguity. Participants, therefore, often found it difficult to locate Aun's body ethnically and/or "racially":

Scott: I'm not too sure about [Karim Aun], I don't know if it's just the image they've got, he could be white or he could be mixed race, I'm not entirely sure, but I think that's just the way the photo's taken and it's hard to tell for me personally.

Sam: He looks White to me but you might tell me he's mixed race or something like that.

Sebastian: he looks like he's probably more half-caste [sic] I think than probably Black anyway, so he's probably got that kind of quite olivey skin tone which, to be fair, it's something a lot of people look tanned and healthy and again it's a sign of health generally, tans and darker skin. But ethnicity, I didn't really think about it in that way ...

Moreover, Dan even goes as far as to suggest, “this Karim guy doesn't have a White person's face." Such assertions highlight the significant position the body and physiognomy still occupies in the politics of race, as well as how the boundaries between whiteness, "mixedness," and otherness are contingent, porous, and perpetually contested.

The second image is of Juan Manuel Vargas Risco, a professional footballer and former captain of the Peru national team who is relatively unknown in Britain, even to football enthusiasts. Despite this, Vargas is cast as the lead character in the Umbro marketing campaign the image is 
promoting. The camera captures Vargas gazing away from the lens, sitting in a tattoo studio, as if he were about to add to an already impressive collection of tattoos on his arms. Unlike Aun, he is presented in full color, his skin is brown, his hair is dark and swept across his forehead, and he also wears neatly styled facial hair around his mouth and chin. Like Aun, Vargas, too, is read differently and inconsistently by different people:

Paul: Is that guy [points to Juan Vargas] White or Black? Can't tell. Is he White? Not too sure on that one.

David: Well if you sat me down and you gave me all those pictures and you said "Right, pile of White people, pile of Black people” ...Juan Vargas...I'd have to put in an "other" pile.

The men's willingness to collapse complex ethnic and racialized identities into a discussion primarily based on skin color is telling insomuch as it alludes to a learned ignorance, one that leaves Aun and Vargas in ambivalent "racial" and ethnic territory. These unruly, racialized bodies appear as objects out of line (Ahmed 2006); they disorientate and disturb racialized "certainties" by breaking rank from established (but certainly not fixed) racialized and masculinized discourses of embodiment.

\section{White Heterosexual Men and the Pleasures of Unruly Athletic Bodies}

Despite the failure of participants to locate him, Sebastian, Carl, James, Bradley, Jason, Paul, Neil, Terry, and Dan all singled out Aun from the set of twelve images as the person they "would most like to be like." Being out of line is certainly not absolutely negative and/ or disturbing. Here, I wish to recognize the expediency of Hall's $(1997,225)$ "spectacle of the 'Other'," given it helps me explores how popular conceptions of racialized difference have been worked through a fascination with and fetishization of the other; a racialized frame through which many are taught to gaze and conceive of the world. Terry and Dan explain why they were drawn to Aun: 
This is the author's version of a journal article published in Men and Masculinities in 2019

Terry: He's a good-looking bloke and [has] a great body, smiling, looks like he's a very happy guy ... Nice smile, you know, he's just not someone that looks ugly, he ain't got, doesn't look like he's got any blemishes, ain't got any teeth missing, cheekbones, structure, face structure, just looks a half decent looking bloke ... he's more tanned, even though it's [a] black and white [picture], looks a bit more tanned, a bit more color to him. This one's got a tattoo, I like tattoos, like body art.

Dan: But if I was going for women, I'd be taking [Karim Aun], I would, look at him! If you went out for one night as him you would be swimming in it. I think women prefer tanned guys.

In both instances, the men agree that Aun's desirability is drawn out of and read into the racialized aspects of his body, one that cannot be neatly categorized as "white." His physique, which participants believed was well muscled, his tattoos, "tanned" skin, and friendly, "exotic" appearance were all cited as attractive features-challenging simplistic conclusions about whiteness as powerful and blackness as submissive (Mac an Ghaill 1999). Aun appears as the perfect emblem of contemporary Western market-ready masculinity: "multiracial, de-politicized, and lacking any serious racial allegiance" (Dagbovie 2007, 225). For a significant number of men in this study, Aun was indeed both unruly, an other, an "everyman" even; but nonetheless he was read unequivocally as an especially pleasurable body.

As opposed to those male bodies in the original sample of twelve images, who were racialized by participants' as "Black" or “colored," and who were subsequently labeled by Sebastian, Paul, Jamie, and Phillip as "obvious[ly]" different- which is at odds with previous research that has pointed to the homoerotic pleasure attached to bodies racialized as black (Gilligan 2012; Carrington 2002, 2010)-the aspirational interpretations of certain male bodies is a move that marks unruly, racialized athletic bodies both favorably and inauspiciously. In this sense, unruliness is not conceived as a state that is a dilution of "purer" racialized identities; they illustrate how processes of unruly racialization may render others "more powerful in certain arenas" (Nayak 2005, 145), more aspirational, perhaps more utopic even. In the wake of a notable increase in the number of bodies racialized as unruly, excelling in athletic cultures, there is a need to understand how media representations are received and interpreted by 
This is the author's version of a journal article published in Men and Masculinities in 2019

consumers. The testimonies of the men in this research then suggests that historical narratives of "mixedness," which-mainly via white male politicians, journalists, and scientists-have for centuries shaped and pathologized bodies that challenge racialized certainties (see Ifekwunigwe 2004), are shifting.

The concept of the exotic, "multiracial" female other is well established (Vasquez 2010; Waring 2013). However, the rise in scholarship linking heterosexual men to sexually ambiguous behaviors and practices points to a need to understand othered male bodies as events that these men, too, find pleasurable. This productive conception of pleasure and otherness implies that the appeal of and fascination with the other extends beyond the fantasies of white university jocks and their misogynistic crusades and fictions: "bodies, objects and worlds cometogether as well as break apart" (Ahmed 2014, 94). The ascription of exotic value is more than a wholly and structurally repressive strategy since it also infers productive, cultural dialogue and exchange between male bodies.

To further this point, admiration for Internet microcelebrity, Aziz "Zyzz" Sergeyevich Shavershian2 -a subcultural icon who a number of young white British gymgoers spoke of during observations-illustrates how white heterosexual men have shifted their gaze to afford certain unruly, racialized others cult status (Fuller and Page Jeffery 2017; Nansen et al. 2016). Aun and Zyzz-whose names both imply Arab ancestry, who have tattoos laden over brown, muscular bodies, and who were born outside but lived in Australia-are suitable homoerotic visuals that challenge (but do not entirely overthrow) the hegemonic status of idealized white male athletic bodies salient in sport and leisure media. To look through the eyes of a specially sanctioned other, to be embodied as the other, to walk through the world without "a White person's face," is a fantasy emergent from deeply homoerotic contemplations. Considering the recent rise in overtly homoerotic behavior in all-male athletic cultures, the utilities of the concept of exoticization, here, go beyond an infatuation with exotic women and extend to the interactions between certain groups of men.

In contrast, Vargas was a body that divided opinion on more matters than simply his ethnicity. That is, gazing at the other and experiencing pleasure points to the racialized body's "multidiscursive and polysemic value across a number of sites" (Nayak 2005, 145). Sam, Terry, 
This is the author's version of a journal article published in Men and Masculinities in 2019

and Carl complimented Vargas' tattoos; Sam was especially keen to explain how he related to Vargas:

I would say I looked more like him, not features-wise obviously ...I mean, I look at his tattoos and I think them look good and I relate to that I suppose as well.

Here, Sam identifies with Vargas; he sees himself reflected in a body he is unable to locate as white. However, other participants interpreted Vargas and his tattoos less favorably. Unlike Sam, Terry, and Carl, these men saw Vargas' tattoos as markers of gangsterism and criminality:

Paul: I think that [Vargas] looks awful, all [those tattoos] down the arms and stuff... he looks like a gang member and doesn't look like he would be a sportsman ... unfortunately that's the impression it gives to me.

Neil: I am totally against tattoos for a start and I think he just portrays the wrong image ... that you can have a tattoo and it is good for you. It seems acceptable but I don't think it should be. He looks like a gangster and a criminal!

White heterosexual men, of course, do not have universal and unproblematic relationships with Aun and Vargas. Their bodies invite myriad interpretations from white heterosexual men. Even so, outright rejections of their relatability were not forthcoming from participants. As Ahmed (2006) puts it, they are "... the exotic other that can just be seen on the horizon" (116), lingering in view. Distant. But "reachable." If only just. In this space then, between the voyeur and the object, just as the horizon and its knowability changes depending on where we gaze at it from, the value and meaning of unruliness invariably "floats." Bodies racialized as unruly, as well as the meaning of pleasure, are never fixed finally as empowered/oppressed, homosexual/heterosexual or philogynistic/ misogynistic, self/other, and so on. It is plausible that "pleasure" means all of the above, at the same time. But while the bodies of Aun and Vargas remain at a distance-meaning they "embody distance" (Ahmed 2014, 98)-their perceived proximity is significant. I elaborate on this conclusion in the following section.

\section{Embodying Unruliness: Distorting Racialized Lines}


This is the author's version of a journal article published in Men and Masculinities in 2019

Recognizing homoerotic pleasure is not necessarily indicative of sex-desire, or changing attitudes toward sexuality, which is certainly not to deny this is never the case, allows for an important epistemological opportunity. That is, understanding homoeroticism not as a desire nor material act per se allows us to read men's responses to other male athletic bodies as something entirely more complex than a proxy discussion of men's sexuality and/or their attitudes toward the sexuality of others-a trap into which much "inclusive masculinity" theory falls. A willingness to gaze at and find pleasure in a variety of male athletic bodies then speaks to the changing ways men discursively (de)construct contemporary notions of manhood and to the blurring of boundaries between discourses of homosociality and homoeroticism. In other terms, it allows men to think about their bodies differently and to embark on projects that change their corporeality.

Indeed, discussions with the white heterosexual men who took part in this study, about the various and differently racialized athletic bodies contained in the original sample, revealed a desire to change their bodies. That is, they did not see themselves as spectacular, privileged, powerful, or hegemonic, which, of course, does not mean they are not any of these things. Participants commonly described themselves as "normal" and/or "average." A common complaint participants had when asked about their own bodies was that they felt they could or should become more muscular, be fitter or "do better." Paul explains: "[i]t's not necessarily that I'm content, because I would like to tone up and I realise the benefits." This theme, which ran through testimonies, points to a level of dissatisfaction rooted in the aesthetics of the white male body. Sebastian explains how the unruly, racialized body offers an aesthetic template that he actively pursues:

[Aun is j]ust very, you know, everything looks in proportion, looks very happy. Yeah, he's got a couple of little tattoos on the top but they are quite discreet in a way that if he's wearing a shirt or whatever else it wouldn't be like "Look at me, look how big and aggressive I am," he just looks like he's very comfortable in his own skin ... . I think he's got a lot of manliness about him and the way he looks and some of the tattoos on his arms, but not too much that it's out of the way and again he just looks fairly clean shaven, looks after himself ... he's more of a half-caste than anything else but it's just the 
This is the author's version of a journal article published in Men and Masculinities in 2019

fact he looks confident in what he is. Obviously I'm not half-caste but he still looks fairly close to the kind of image that I would want to see for myself.

During discussions about bodies, participants displayed a tacit awareness of the racialized significance of certain signs, as well as their own bodies. While spending time in gyms and training with traceurs, 3 I observed several white men who wore tattoos that resembled closely the style of both Aun and Vargas, particularly the full sleeve tattoo.4 Sam a forty-seven-year-old, white-collar worker, who had graduated to his current position from more labor-intensive work as a young man, for instance, has a full sleeve design covering his left arm, which includes Christian iconography reminiscent of a cholos gang member. Cris, too, owned a full sleeve, Maori-style design, while Justin was keen to show me a collection of Japanese-inspired pieces on his back and upper arms. The political significance of tattoos in contemporary popular culture, as symbols of otherness, gangsterism, criminality, alternative subcultural spaces (such as rap, grime, and $\mathrm{R} \& \mathrm{~B}$ music) and sport (such as basketball) are long established and well documented. Indulging in and experimenting with styles and practices marked as other, these men who identify as "white British" are engaged to disturb their own "racial lines" or, at the very least, change their course.

Understanding that participants engage in corporeal practices designed to "improve" or modify their bodies speaks to how it is participants are seemingly unaware of their white male privileges; their desire to change their bodies alludes to a sense of their own mediocrity. An extract from my research diary furthers this point:

The group of men with whom I'd been training [in the gym] the previous day had invited me along to use the sauna and spa facility with them, after training ... . After getting back into the changing rooms, and out of the shower, I started to dry off. Suddenly, A commotion ensued on the other side of the changing room. It was the guys I had been training with. "You went in first last time Mark!" I heard one of them say. "Yeah I know but the missus is waiting for me downstairs so I've gotta be quick, tonight!” Mark replied. "Well, be quick or we won't all get a go before it closes," said a third voice. And as I had been used to when I had worked in gyms before, these men were quite nonchalantly playfighting over who would use the sunbed first. 
This is the author's version of a journal article published in Men and Masculinities in 2019

Furthermore, during observations I learned that a significant minority of men with whom I was training were also seeking to turn their skin brown but were injecting Melanotan (a drug designed to stimulate the skin to produce more melanin), a practice which aims to achieve precisely the opposite of what has been called "whitewashing"-a racialized practice associated with skin whitening in communities of color. In this way, the body acts as a "corporeal canvas for ethnic experimentation" (Nayak 2008, 172), a malleable entity able to counter the triteness that is perceived to be signified by an abundance of markers of whiteness. Such drastic and risky forms of embodied appropriation are pursued in the hope these white men might achieve a corporeal resemblance to Aun, Shavershian, and Vargas.

For the participants of this study then, "improving" on one's body was a strategic form of appropriation, impelled by changing racialized frames and heteromasculine gazes. Simply, being "too white," in the somatic sense, for those operating in the athletic cultures I observed was problematic. The adoption of racialized markers then function as part of a selective commodification of otherness-a process whereby certain racialized signs (e.g., tattoos and brown skin) are endorsed by mainstream media imagery and quite literally advertised for sale in sunbed shops, online pharmacies, and tattoo studios. Hence, such practices enable some of the white heterosexual men in this study to engage in resistive body projects in that they "take the very 'affects' of mixing, or coming into contact with things that reside on different lines, as opening up new kinds of [racialized] connection" (Ahmed 2006, 154, 155). These men are connected through an embodied conversation, a somatic dialogue that makes and remakes the limits of racialized pleasure and expands the boundaries for homoerotic potential.

This line of argument however is not to be confused with a desire to escape forever the phenotypic privileges that are associated with being read as white, male, and heterosexual nor is it suggesting white male supremacy is a system participants worked proactively against reproducing. As Hooks ([1992] 2004, 367) notes, "an encounter with the Other, does not require that one relinquish forever one's mainstream positionality." Sam explains:

It's like my mate Dave ... he's just a normal White guy but everybody thinks he's Iranian and all sorts of things because he's got the features and he's maybe if he's had a few 
holidays and he catches the sun and when he hits the sun he does go dark, and people have thought he's all sorts, they've thought he's bloody Pakistani, Iranian, Iraqi! And he's not!

Sam's eagerness to convince me Dave is a "normal white guy" (read: a subject) and that he is definitely not "all sorts" like "bloody Pakistani, Iranian, Iraqi!" (read: objects) is telling. That is, while adopting embodied markers of otherness is presumably pleasurable for him, this practice must not be so convincing that the body is actively read as other. The distance that is embodied must not extend "to the other side of the world" (Ahmed 2014, 98). Being able to return to the comfort and convenience of phenotypic whiteness, its unearned privileges and supremacy, is a journey white bodies must be capable of making. White heterosexual men are in this way linked implicitly to the exercise of power and the regulation of racialized hierarchies insofar as they utilize eroticization and appropriation as social control. In other terms, not only do they recognize and ascribe seemingly positive social value to unruly racialized athletic bodies, at the same time, they encourage a somatic seizure of those unruly racialized signs, thus affording white men the ultimate white male privilege: the best of both bodies. This, perhaps, is the ultimate white male privilege.

\section{Concluding Remarks}

I wish to end this article by first pointing to the ways in which unruly racialization allows for homoerotic appreciations of othered male athletic bodies. New ways of being emerge from racialized inspections in that homoerotic gazing frames male athletic bodies as nuanced, consumerized, and historically contingent cultural canvases. To this end, we might say that gazing at bodies in such a way reveals how the participants of this study are continually working through and forming new attitudes and orientations toward multiracial societies. After gazing at male athletic bodies, the surrounding discussions then were able to articulate a racialized politics that, in turn, reveal some white heterosexual men's confusion: that is, "whether to control blackness on the one hand or encourage racial harmony on the other, or perhaps to abandon race altogether" (Dagbovie 2007, 219). Participants' embodied and discursive moves toward and away from otherness are emblematic of such confusion. This serves only to remind us that we remain stuck in a late modern quagmire of "pre- post-race," an epoch in which 
This is the author's version of a journal article published in Men and Masculinities in 2019

racialized, gendered, and sexualized power relationships still exist but in increasingly complex ways.

More empirical research, therefore, is needed, especially in a British context, to understand better how white heterosexual men help reproduce gender-race hierarchies while, simultaneously, lavishing those bodies racialized as unruly with cultural value (Bonilla-Silva 2011; Cashmore 2012). Before we are swept away by some gloriously liberating homily of absolute social improvement then, or one that puts us on the cusp of postraciality, it is important to stress that, as I argue above, gazing at bodies racialized as unruly does not necessarily produce gloriously progressive or transformative postracial outcomes. Indeed, while there are resistive aspects to participants' testimonies and performances of their bodies that draw from a multitude of racialized discourses, the shifting of racialized notions of pleasure cannot be assumed to produce resplendently liberating postracial credos because they have unequal and unpredictable outcomes. While under certain conditions some white heterosexual men are seemingly approving of bodies racialized as unruly and that pleasure of the homoerotic kind is found through the act of looking at those bodies, it is equally important to warn against overstating the structural significance of such observations. Centuries of white heterosexual male domination are not easily undone or reversed in a matter of decades.

\section{Declaration of Conflicting Interests}

The author(s) declared no potential conflicts of interest with respect to the research, authorship, and/or publication of this article.

\section{Funding}

The author(s) received no financial support for the research, authorship, and/or publication of this article.

Notes

1. Men's Health magazine claims Aun is a professional boxing instructor. However, a Google search leads to his sizable modeling portfolio, hosted on the website of highly reputable 
This is the author's version of a journal article published in Men and Masculinities in 2019

modeling agency, Ford Models-a detail Men's Health omits from their image and brief accompanying article.

2. On August 5, 2011, Internet celebrity Aziz "Zyzz" Shavershian died after suffering a heart attack while holidaying in Bangkok, Thailand. Zyzz was a twenty-two-year-old amateur bodybuilder, at the time of his death, and was of "mixed" heritage. A resident of Sydney, Australia, Zyzz became an Internet celebrity after posting numerous pictures of his physique on the Internet, which was well muscled, and to date has accrued more than 140,000 followers on the social networking site, Facebook.

3. A "full sleeve" is a term which commonly refers to a collection of tattoos that covers most or a person's entire arm, from shoulder to wrist.

4. A traceur is the name given to a male practitioner of parkour.

5. The term cholo is often used to refer to a Hispanic male who dresses in chinos, a sleeveless, or flannel shirt with only the top buttoned, a bandana around the forehead and black ink tattoos based on Catholic iconography

\section{References}

Ahmed, Sara. 2000. Strange Encounters: Embodied Others in Post-coloniality. London: Routledge.

Ahmed, Sara. 2006. Queer Phenomenology: Orientations, Objects, Others. Durham, NC: Duke University Press.

Ahmed, Sara. 2014. "Mixed Orientations." Subjectivity 7:92-109.

Azzarito, L. 2009. "The Panopticon of Physical Education: Pretty, Active and Ideally White." Physical Education \& Sport Pedagogy 14:19-39.

Beltra 'n, Mary, and Camilla Fojas'. 2008. "Introduction: Mixed Race Hollywood Film and Media Culture.” In Mixed Race Hollywood, edited by Mary Beltran and Camilla Fojas', 1-22. New York: New York University Press. 
Bhattacharyya, G., J. Gabriel, and S. Small. 2016. Race and Power: Global Racism in the Twenty First Century. Routledge.

Blaisdell, B. 2006. Critical Race Theory as Dialogic Performance with white Teachers: Addressing Colorblindness. Chapel Hill: The University of North Carolina at Chapel Hill.

Bonilla-Silva, E. 2011. "The Invisible Weight of Whiteness: The Racial Grammar of Everyday Life in Contemporary America." Ethnic and Racial Studies 35:173-94.

Brah, A. 1996. Cartographies Ofdiaspora. London and New York: Routledge.

Burdsey, Daniel. 2004. "'One of the Lads'? Dual Ethnicity and Assimilated Ethnicities in the Careers of British Asian Professional Footballers.” Ethnic and Racial Studies 27:75779. doi: $10.1080 / 0141987042000246336$.

Burdsey, Daniel. 2006. “'If I Ever Play Football, Dad, Can I Play for England or India?' British Asians, Sport and Diasporic National Identities." Sociology 40:11-28. doi: 10. 1177/0038038506058435.

Burgess, R. G. 1991. In the Field: An Introduction to Field Research. London: Routledge.

Carrington, B. 2002. "Fear of a Black Athlete: Masculinity, Politics and the Body." New Formations 45:91-110. Carrington, B. 2008. ““What's the Footballer Doing Here?" Racialized Performativity, Reflexivity, and Identity." Cultural Studies \$ Critical Methodologies 8:423-52. doi: 10.1177/1532708608321574.

Carrington, B. 2010. Race, Sport and Politics: The Sporting Black Diaspora. London, UK: Sage.

Cashmore, E. 2012. Beyond Black: Celebrity and Race in Obama's America. London: Bloomsbury Academic.

Conquergood, D. 1991. "Rethinking Ethnography: Towards a Critical Cultural Politics." Communication Monographs 58:179-94.

Dagbovie, Sika Alaine. 2007. "Star-light, Star-bright, Star Damn Near White: Mixed-race Superstars." The Journal of Popular Culture 40:217-37. doi: 10.1111/j.1540. 5931.2007.00376.x.

Frankenberg, R. 1993. White Women, Race Matters. The Social Construction of Whiteness. London: Routledge. 
This is the author's version of a journal article published in Men and Masculinities in 2019

Fuller, Glen, and Catherine Page Jeffery. 2017. “'There is no Zyzz': The Subcultural Celebrity and Bodywork Project of Aziz Shavershian.” Celebrity Studies 8:20-34. doi: 10.1080/ 19392397.2016.1190287.

Garner, S. 2006. "The Uses of Whiteness: What Sociologists Working on Europe Can Draw from US Research on Whiteness.” Sociology 40:257-75. doi: 10.1177/ 0038038506062032.

Garner, S. 2007. Whiteness: An Introduction. London: Routledge.

Garner, S. 2017. "Surfing the Third Wave of Whiteness Studies: Reflections on Twine and Gallagher.” Ethnic and Racial Studies 40:1582-97.

Gilligan, Sarah. 2012. "Fragmenting the Black Male Body: Will Smith, Masculinity, Clothing, and Desire." Fashion Theory: The Journal of Dress, Body \& Culture 16:171-92. doi: $10.2752 / 175174112 \times 13274987924050$.

Gilroy, P. 2005. Postcolonial Melancholia. New York: Columbia University Press.

Gilroy, P. 2017. "Under the Skin with Russell Brand.” In Who Are the Slaves Now?, edited by B. Russell.

Gold, R. 1958. "Roles in Sociological Field Observations.” Social Forces 36:217-23.

Hall, S. 1997. "The Spectacle of the 'Other'." In Representation: Cultural Representations and Signifying Practices, edited by S. Hall. London: Sage \& Open University.

Hall, Stuart. 1998. "Cultural Identity and Diaspora." In Identity: Community, Culture, Difference, edited by J. Rutherford, 222-37. London, UK: Lawrence \& Wishart. (Originally work published 1990)

hooks, B. 1992. Black Looks: Race and Representation. London, UK: Routledge. Hooks, B. 2004. "Eating the Other: Desire and Resistance." In Media and Cultural Studies: Keyworks, edited by Meenakshi Gigi Durham and Douglas Kellner, 366-80. Oxford, UK: Blackwell. (Originally work published 1992)

Howe, P. David. 2011. "Cyborg and Supercrip: The Paralympics Technology and the (Dis)empowerment of Disabled Athletes." Sociology 45:868-82. doi: 10.1177/ 0038038511413421.

Hughey, Matthew W. 2011a. "Backstage Discourse and the Reproduction of White Masculinities." Sociological Quarterly 52:132-53. doi: 10.1111/j.15338525.2010.01196.x. 
This is the author's version of a journal article published in Men and Masculinities in 2019

Hughey, Matthew W. 2011b. "Color Capital, White Debt, and the Paradox of Strong White Racial Identities.” Du Bois Review: Social Science Research on Race FirstView:1-32. doi: $10.1017 /$ S1742058X11000506.

Hylton, Kevin. 2009. "Race" and Sport: Critical Race Theory. London, UK: Routledge. Hylton, K. 2012. "Talk the Talk, Walk the Walk: Defining Critical Race Theory in Research.” Race Ethnicity and Education 15:23-41.

Hylton, K., and S. Lawrence. 2016. “'For your Ears only!'Donald Sterling and Backstage Racism in Sport." Ethnic and Racial Studies 39:2740-57.

Ifekwunigwe, Jayne O. 2004. "Introduction: Rethinking 'Mixed Race' Studies." In "Mixed Race” Studies: A Reader, edited by Jayne O. Ifekwunigwe, 1-36. London, UK: Routledge.

Kvale, S. 1996. An Introduction to Qualitative Research Interviewing. California: Sage Publications.

Lawrence, S. 2013. “On White Men's Representations of 'Race', Whiteness, Masculinities and 'Otherness': A Critical Race study of Men's Magazines, Racialisation and Athletic Bodies." PhD diss., Leeds Metropolitan University.

Long, Jonathan, and Kevin Hylton. 2002. "Shades of White: An Examination of Whiteness in Sport.” Leisure Studies 21:87-103.

Long, J. 2007. Researching Leisure, Sport and Tourism: The Essential Guide. GB: Sage Publications Ltd.

Mac an Ghaill, M. 1999. Contemporary Racisms and Ethnicities: Social and Cultural Transformations. Buckingham: Open University Press.

Markula, Pirkko, and Richard Pringle. 2006. Foucault, Sport and Exercise: Power, Knowledge and Transforming the Self. London, UK: Routledge.

Meer, Nasar, and Nayak Anoop. 2015. "Race Ends Where? Race, Racism and Contemporary Sociology." Sociology 49:3-20.

Nansen, Bjorn, Michael Arnold, Martin Gibbs, Tamara Kohn, and James Meese. 2016. Remembering Zyzz-Distributed Memories on Distributed Networks. Basingstoke, UK: Palgrave Macmillan.

Nayak, Anoop. 2005. "White Lives." Racialization: Studies in Theory and Practice 141-62. Nayak, A. 2007. "Critical Whiteness Studies.” Sociology Compass 1:737-55. doi: 10.1111/j. 1751-9020.2007.00045.x. 
Nayak, A. 2008. Darkest Whiteness: Race, Class, and Culture in Global Times. In Telling Young Lives: Portraits in Global Youth, edited by C. Jeffrey and J. Dyson, 162-73. Philadelphia, PA: Temple University Press.

Radley, A., and D. Taylor. 2003. "Images of Recovery: A Photo-Elicitation Study on the Hospital Ward.” Qualitative Health Research 13:77-99.

Robinson, Sally. 2013. Marked Men: White Masculinity in Crisis. New York: Columbia University Press.

Ryu, Won Hyung A. 2005. “A Semiotic Study on the Transworld Skateboarding Magazine.” Semiotica: Journal of the International Association for Semiotic Studies/Revue de l'Association Internationale de Se'miotique 157:305-13.

Shilling, Chris. 2007. "Sociology and the Body: Classical Traditions and New Agendas." The Sociological Review 55:1-18. doi: 10.1111/j.1467-954X.2007.00689.x.

Thorpe, Holly. 2008. "Foucault, Technologies of Self, and the Media." Journal of Sport \& Social Issues 32:199-229. doi: 10.1177/0193723508315206.

Twine, F. W., and C. Gallagher. 2008. "The Future of Whiteness: A Map of The 'Third Wave'." Ethnic and Racial Studies 31:4-24.

Vasquez, Jessica M. 2010. "Blurred Borders for Some But Not "Others": Racialization, "Flexible Ethnicity," Gender, and Third-generation Mexican American Identity." Sociological Perspectives 53:45-72. doi: 10.1525/sop.2010.53.1.45.

Waring, Chandra D. L. 2013. “"They See Me as Exotic ... That Intrigues Them”: Gender, Sexuality and the Racially Ambiguous Body.” Race, Gender \& Class 20:299-317.

Young, I. 1990. Justice and the Politics of Difference. Princeton: Princeton University Press

\section{Author Biography}

Stefan Lawrence is senior lecturer at Newman University, Birmingham and founder of the Digital Football Network. 